\title{
A study of antibiotic used in paediatric inpatients at Jawaharlal Nehru Institute of Medical Sciences, Manipur: a retrospective study
}

\author{
Laitonjam Jonita Devi, Varkung Valte, Oinam Joychandra*
}

Department of Pharmacology, Jawaharlal Nehru Institute of Medical Sciences, Porompat, Imphal, India

Received: 18 January 2020

Accepted: 02 March 2020

*Correspondence:

Dr. Oinam Joychandra,

Email: joyoinam2007@redffmail.com

Copyright: (C) the author(s), publisher and licensee Medip Academy. This is an open-access article distributed under the terms of the Creative Commons Attribution Non-Commercial License, which permits unrestricted non-commercial use, distribution, and reproduction in any medium, provided the original work is properly cited.

\section{ABSTRACT}

Background: The therapy of antibiotics among the paediatric patients may produce any type of adverse effects as the organs of infants and children are immature and the genetic constituents are also not fully known. The empirical use of antibiotic may also produce antibiotic resistance. Aim was to study the prescribing pattern of antibiotics among the paediatric patients.

Methods: It was a retrospective, observational study for a period of six months. The collected data included age, sex, diagnosis and line of management. Generic name and average cost of treatment per patient was evaluated by using CIMS 2019 and Bhartiya Jan Aushadhi Pariyojna. The descriptive statistics was applied for the detail data analysis.

Results: Bed head tickets (BHTs) of 560 inpatients was examined. The common diagnosis were AGE (193; 34.4\%) and ARI $(60 ; 10.7 \%)$. The route of administration were oral $279(49.8 \%)$ and parenteral $281(50.1 \%)$. The duration of hospital stay were in between 5 days $(141 ; 25.1 \%)$ to 7 days $(61 ; 10.8 \%)$. The minimum and maximum age of the patient were 3 months and 12 years respectively. The most common antibiotic used was ceftriaxone and metronidazole. The number of patient received single antibiotic was 295 (52.6\%) and multiple used was 265 (47.3\%). The number of antibiotic prescribed from NLEM and Pariyojna were 9 and 13 respectively. The average cost of treatment per patient was Rs. 345.00 (CIMS) and Rs. 119.90 (Pariyojna) approximately.

Conclusions: The antibiotics prescribed by generic name was not satisfactory. The proposal for wide awareness programme may be suggested to the concerned authority for improving the prescribing practice among the physicians at different levels.

Keywords: Antibiotic, BHTs, Generic, NLEM, Parenteral, Prescription

\section{INTRODUCTION}

Paediatric patients includes neonate, infant and children. The problems of paediatric patients who were hospitalised for infections along with diarrhoea, dehydration and breathlessness are solved by the treating physician at their best level. The management of paediatric patients are very delicate, need experienced and trained supporting staffs, specific equipments and instruments. Once the paediatric patients are admitted in the hospital, the patients used to stay not less than 48 hours. Over and above the tenderness of the patients, major vital organs like liver, kidneys etc. are also immature. They are highly susceptible to infections due to immature immune system. ${ }^{1}$ Uses of antibiotics has become a routine practice for the treatment of paediatric illness ${ }^{2}$. With the raise in healthcare cost, over prescription of antibiotics in paediatric patients has led to induction of antibiotic resistance and super infection. ${ }^{3-5}$ Therefore, the present study was aimed to study the prescribing patterns of antibiotics to the paediatric patients by collecting the hospital bed head tickets (BHTs) of inpatients of Paediatric Department JNIMS Hospital for a period of 6 months. 


\section{METHODS}

It was a retrospective observational study of the hospital BHTs for a period of 6 months (January 2019 to June 2019). 600 BHTs were screened for the study. Out of 600,40 were rejected due to leave against medical advice (LAMA), death within 10 hours of admission and improper BHT and only 560 bed head tickets were selected for the study. Data collected from the case sheets were name, age, sex, address, parents name of the patients, diagnosis, antibiotic used, route of antibiotic administration, co-administered drugs and the number of days of hospital stay. Permission of the study for the BHTs was obtained from medical superintendent (MS) and medical record office (MRO), JNIMS hospital. All the collected data are analysed by using SPSS and descriptive statistical method.

\section{RESULTS}

Of the total 560 patients, $317(56.6 \%)$ were male and 243 (43.4\%) were female. Maximum number of patients who got antibiotic prescription was in between the age group of 1 to 3 years i.e. $218(38.9 \%)$ as shown in Table 1 .

Table 1: Padiatric inpatients characteristics.

\begin{tabular}{|llll|}
\hline Age groups & \multicolumn{1}{c|}{ Male $(\%)$} & Female $(\%)$ & Total $(\%)$ \\
\hline 0-1 month & $9(1.6)$ & $9(1.6)$ & $18(3.2)$ \\
\hline 1-12 months & $75(13.4)$ & $56(8.2)$ & $121(21.6)$ \\
\hline 1-3 years & $121(21.6)$ & $97(17.3)$ & $218(38.9)$ \\
\hline 3-6 years & $49(8.8)$ & $46(8.2)$ & $95(16.9)$ \\
\hline 6-12 years & $63(11.3)$ & $45(8)$ & $108(19.3)$ \\
\hline Total & $317(56.6)$ & $243(43.4)$ & $560(100)$ \\
\hline
\end{tabular}

Table 2: Antibiotic exposure in paediatric patients with respective route of administration.

\begin{tabular}{|c|c|c|c|c|c|c|}
\hline Class & Antibiotics & Frequency (\%) & Male (\%) & Female (\%) & Oral (\%) & Parenteral (\%) \\
\hline \multirow{4}{*}{ Cephalosporin } & Ceftriaxone & $200(35.7)$ & $118(21.1)$ & $82(14.6)$ & - & $200(100)$ \\
\hline & Cefpodoxime & $44(7.8)$ & $23(4.1)$ & $21(3.8)$ & $44(100)$ & - \\
\hline & Cefixime & $62(11.1)$ & $34(6.1)$ & $28(5)$ & $32(5.7)$ & $30(5.4)$ \\
\hline & Cefitoren & $8(1.4)$ & $6(1.1)$ & $2(0.4)$ & $8(100)$ & - \\
\hline \multirow{3}{*}{ Aminoglycosides } & Amikacin & $42(7.5)$ & $25(4.5)$ & $17(3.0)$ & - & $42(100)$ \\
\hline & Gentamycin & $1(0.2)$ & $1(0.2)$ & - & - & $1(100)$ \\
\hline & Walamycin & $1(0.2)$ & - & $1(0.2)$ & - & $1(100)$ \\
\hline \multirow{4}{*}{ Beta-lactam } & Amoxicillin & $28(5)$ & $20(3.6)$ & $8(1.4)$ & $27(96.4)$ & $1(0.2)$ \\
\hline & Imipenem & $2(0.3)$ & $1(0.2)$ & $1(0.2)$ & - & $2(100)$ \\
\hline & Piperacillin & $2(0.3)$ & $1(0.2)$ & $1(0.2)$ & - & $2(100)$ \\
\hline & Ampicillin & $2(0.3)$ & $2(0.4)$ & - & - & $2(100)$ \\
\hline Macrolides & Azithromycin & $16(2.8)$ & $9(1.6)$ & $7(1.3)$ & $16(100)$ & - \\
\hline Polypeptide & Polymyxine & $5(0.3)$ & $1(0.2)$ & $4(0.7)$ & $5(100)$ & - \\
\hline \multirow{2}{*}{ Quinolones } & Ofloxacin & $31(5.5)$ & $15(2.7)$ & $16(2.9 \% 0$ & $31(100)$ & - \\
\hline & Norfloxacin & $3(0.5)$ & $2(0.4)$ & $1(0.2)$ & $3(100)$ & - \\
\hline Nitroimidazole & Metronidazole & $113(20.2)$ & $59(10.5)$ & $53(9.5)$ & $113(100)$ & - \\
\hline
\end{tabular}

The class of antibiotics which was most frequently prescribed was Cephalosporin group- Ceftriaxone $(35.7 \%)$, Cefixime $(11.1 \%)$, Cefpodoxime $(7.8 \%)$ followed by Aminoglycosides- Amikacin (7.5\%), Quinolones- Ofloxacin (5.5\%), Beta-lactam- Amoxycillin (5\%), Macrolides- Azithromycin (2.8\%). Over and above the already mentioned antibiotics, there is also an antibiotic like antiprotozoal drug i.e. Metronidazole $(20.2 \%)$ which was used in many of the management of infections, shown in Table 2.

The number of patients received single antibiotic in the age group of 0 to 1 month was 9 (1.6\%), 1 to 11 months $53(9.5 \%), 1$ to 3 years $107(19.1 \%), 3$ to 6 years 60 $(10.7 \%), 6$ to 12 years $66(52.6 \%)$ respectively. Number of patients received multiple antibiotics in the age group 0 to 1 month was $9(1.6 \%), 1$ to 11 months 68 (12.1\%), 1 to 3 years $111(19.8 \%), 3$ to 6 years $35(6.2 \%), 6$ to 12 years $42(7.5 \%)$. So the maximum number of patients in age between 1 to 3 years exposed to single antibiotic was 107
(19.1\%) and multiple antibiotic(s) was 111 (19.8\%) respectively. Multiple antibiotics means combination of antibiotics or change of antibiotics during the treatment. For example, combination of ceftriaxone, tazobactam and amikacin for 1 to 3 days and changed to combination of ceftriaxone and tazobactam.

The preferable route of administration of antibiotic was parenteral i.e. from 0 to 1 month was 8 (p), 1 to 11 months 41 (p), 1 to 3 year 107 (p), 3 to 6 years 24 (p), 6 to 12 years was 31 (p). Similarly, antibiotic given orally for age group of 0 to 1 month was 1 (o), 1 to 11 months 12 (o), 1 to 3 years 25 (o), 3 to 6 years 36 (o), 6 to 12 years 35 (o). So, it was observed that with the increasing age of the patients, it seems the preferable route of administration was changed from parenteral to oral, because there may be good compliance between the administrator of the antibiotics, patient and their care taker (Table 3). 
Table 3: Single and multiple antibiotic used in different age groups.

\begin{tabular}{|c|c|c|}
\hline Age groups & Single & Multiple \\
\hline 0-1 month & $\begin{array}{l}9(1.6 \%), p(8) \\
o(1)\end{array}$ & $\begin{array}{l}9(1.6 \%), p(8), \\
o(1)\end{array}$ \\
\hline 1-11 months & $\begin{array}{l}53(9.5 \%), p(41) \\
\text { o }(12)\end{array}$ & $\begin{array}{l}68(12.1 \%), p(43), \\
o(25)\end{array}$ \\
\hline $1-3$ years & $\begin{array}{l}107(19.1 \%), p(82), \\
o(25)\end{array}$ & $\begin{array}{l}111(19.8 \%), p(40), \\
o(71)\end{array}$ \\
\hline 3-6 years & $\begin{array}{l}60(10.7 \%), p(24) \\
\text { o }(36)\end{array}$ & $\begin{array}{l}35(6.2 \%), p(20), o \\
(15)\end{array}$ \\
\hline 6-12 years & $\begin{array}{l}66(11.8 \%), p(31) \\
o(35)\end{array}$ & $\begin{array}{l}42(7.5 \%), p(9) \\
o(33)\end{array}$ \\
\hline Total & $\begin{array}{l}295(52.6 \%), p(186) \\
\text { o }(109)\end{array}$ & $\begin{array}{l}265(47.3 \%), p(120) \\
o(145)\end{array}$ \\
\hline
\end{tabular}

$\mathrm{p}=$ parenteral, $\mathrm{o}=$ oral. Multiple $=$ more than 1 upto 3. $\mathrm{P}=0.009$

(which is significant)

The duration of hospital stay was 1 to 3 days for the age group of 0 to 1 month. Similarly the duration of hospital stay for age group of 1 month to 3 years and upto 12 years was 3 to 7 days. Overall, the minimum number of hospital stay was 1 day and maximum number of hospital stay was 7 days. Out of 16 antibiotics prescribed by the paediatricians, 9 antibiotics were from NLEM (Amikacin, Amoxicillin, Cefixime, Cefpodoxime, Ceftriaxone, Vancomycin, Ofloxacin, Norfloxacin, Metronidazole). ${ }^{15}$ Similarly, 13 number of antibiotics were prescribed from the list of Pradhan Mantri Bhartiya Jan Aushadhi Pariyojna. $^{16}$

The estimated average cost of antibiotic prescription per patient was Rs.345.00 (CIMS) and Rs.119.90 (Pariyojna) approximately (Table 4). ${ }^{16,20}$

Table 4: Most commonly prescribed antibiotics with their approximate expenditure.

\begin{tabular}{|c|c|c|c|}
\hline Antibiotics & Route & $\begin{array}{l}\text { Approx. } \\
\text { expenditure } \\
\left(\mathrm{PY}^{16}\right)\end{array}$ & $\begin{array}{l}\text { Approx. } \\
\text { expenditure } \\
\left(\mathrm{CIMS}^{20}\right)\end{array}$ \\
\hline $\begin{array}{l}\text { Ceftriaxone } \\
\text { +Tazobactam }\end{array}$ & $\begin{array}{l}\text { i.v } \\
\text { (BD) }\end{array}$ & $\begin{array}{l}\text { Rs. } 88.92 / \text { day, } \\
\text { Rs. } 889.2 \text { for } 5 \\
\text { days }\end{array}$ & $\begin{array}{l}\text { Rs. } 326 / \text { day, } \\
\text { Rs. } 1639 \text { for } \\
5 \text { days. }\end{array}$ \\
\hline Cefpodoxime & $\begin{array}{l}\text { Oral } \\
(\mathrm{BD})\end{array}$ & $\begin{array}{l}\text { Rs. } 35.9 \\
(50 \mathrm{ml})\end{array}$ & $\begin{array}{l}\text { Rs. } 65 \\
(50 \mathrm{ml})\end{array}$ \\
\hline $\begin{array}{l}\text { Metronidazole } \\
+ \text { Norfloxacin }\end{array}$ & $\begin{array}{l}\text { Oral } \\
(\mathrm{BD})\end{array}$ & $\begin{array}{l}\text { Rs. } 3.75 \\
(50 \mathrm{ml})\end{array}$ & $\begin{array}{l}\text { Rs. } 18.80 \\
(50 \mathrm{ml})\end{array}$ \\
\hline
\end{tabular}

\section{DISCUSSION}

Antibiotics are most commonly prescribed drugs in paediatric department. ${ }^{6}$ They are beneficial to patient care when prescribed and administered correctly for bacterial infections. ${ }^{7}$ So, prescription writing for the paediatric patient is a challenging practice. The correct diagnosis and specific antibiotic may not be able to achieve all the time. There is the empirical prescription for the suspected organism which cause the infection. ${ }^{8}$ The present study showed the age wise, sex wise distribution of paediatric patient was maximum in the age group of 1 to 3 years i.e. $218(38.9 \%) ; 121(21.6 \%)$ male, $97(17.3 \%)$ female. This finding is almost similar to the observations of Woldu MA et al, Al-Ghazali et al and Chaw PS et al. ${ }^{9-11}$

The class of antibiotic which was prescribed by the paediatricians in this study was Cephalosporin (314; 56.1\%), Aminoglycosides (44; 7.5\%), Betalactam (34; $6.1 \%$ ), Quinolones (34; 6.1\%), Polypeptide (5; 0.3\%). But, the study of Appiah et al show the class of antibiotic prescribed was Aminoglycoside followed by Penicillin but least prescribed was Cephalosporin. However, the findings of Zhang et al showed that Cephalosporins was preferred antibiotic as it does not require skin test prior to administration unlike Penicilin and aminoglycosides which has risk of hearing loss. ${ }^{13}$ Therefore, the present study showed that the paediatricians seemed to prefer Cephalosporins similar to the finding of Zhang et al. ${ }^{13}$

The route of administration of antibiotics was changing from parenteral to oral as the age of the patient is increasing i.e. months to years. This finding is near to the finding of Woldu because the compliance for oral route was better to the older patient. ${ }^{9}$ The age group 1-3 years, the frequency of route administration were change from $82 \%$ to $40 \%$ parenterally, $25 \%$ to $71 \%$ orally.

The frequency of single antibiotic was 107 (19.12\%) and multiple antibiotic was $111(19.8 \%)$, because the antibiotic was changed according to report of microbial test and advice of senior consultant/faculty. As a whole the study observed that single antibiotic used was 295 $(52.6 \%)$ and multiple antibiotic was 265 (47.3\%). The finding was almost near the finding of Woldu but not to Al-Ghazali with no microbial test and specific diagnosis. ${ }^{9,10}$

The maximum number of antibiotic used was in age group of 5 to 12 years and multiple antibiotic used was in age group 1 month to 1 year which was quite away from present findings. But, the route of administration of the present study ( $82 \%$ parenterally) and the number of antibiotic per prescription was almost near to the finding of Labi. ${ }^{12}$

The duration of hospital stay which was observed in this study was minimum of 1 day and maximum of 7 days. This finding was almost similar to finding of Al-Ghazali et al and Chudhury et al. ${ }^{9,14}$

Almost all of the antibiotics which were prescribed are the antibiotics of NLEM 2015 and also Pariyojna. ${ }^{15,16}$ They are not prescribed as generic. The finding was more or less the same of Labi et al and Al-Ghazali et al. ${ }^{9,12}$

Regarding the cost effectiveness for the treatment of the patient during the hospital stay and cost of antibiotic was difficult to ascertain because the price of the antibiotic keep fluctuating and the number and class of antibiotic 
was changing. However, the cost effectiveness of the treatment with the antibiotic seemed to be cheaper with the antibiotic from Pariyojna and Generic class. ${ }^{16}$

\section{CONCLUSION}

The antibiotic prescribing pattern which was observed in this study gave a clue for improving the prescription of antibiotic i.e. strict observation of the guideline of antibiotic policy and stewardship. The goal of rational use initiative is not always to reduce antibiotic use but instead to ensure the use is appropriate. It may be suggested to implement a wide awareness programme about the rational use of antibiotic so that the development of resistance may be minimised.

\section{ACKNOWLEDGEMENTS}

The authors thank the medical superintendent and the MRO of JNIMS Hospital for allowing to study the BHTs of the Paediatric inpatients for the duration i.e. January to June 2019.

Funding: No funding sources Conflict of interest: None declared

Ethical approval: The study was approved by the Institutional Ethics Committee

\section{REFERENCES}

1. Palikhe N. Prescribing pattern of antibiotics in Paediatric Hospital of Kathmandu Village, Kathmandu Univ Med J. 2004;2(1):6-12.

2. Van Houten MA, Luinge K, Laseur M, Kimpen JL. Antibiotic utilisation for hospitalised paediatric patients. Int J Antimicrob Agents. 1998;10(2):161-4.

3. Abula T, Desta Z. Prescribing pattern of drugs in pediatric wards of three Ethiopian hospitals. Ethiop J Health Dev.1999;13(2):135-40.

4. Bhartiy SS, Shinde M, Nandeshwar S, Tiwari SC. Pattern of prescribing practices in the Madhya Pradesh, India. Kathmandu Univ Med J. 2008;6(1):55-9.

5. Moorthi P, Paul R, Srinivasan A, Kumar CS. Irrational use of antibiotics in paediatric prescriptions: A pilot study at community pharmacy in Erode City. Der pharmacia Letthe. 2011;3(3):1717.

6. Jangra S, Bhyan B, Chand W, Saji J, Ghoghari R. To assess prescribing pattern of antibiotics in department of pediatric at tertiary care teaching hospital. $\mathrm{J}$ of Drug Deliv Therap. 2019;9(2):192-6.

7. American Academy of Pediatric dentistry (AAPD). Use of Antibiotic therapy for pediatric dental patients. Available at: https://www.aapd.org/ research/oral-health-policies--recommendations/use- of-antibiotic-therapy-for-pediatric-dental-patients/ Latest revision. 2019 (1-4).

8. Alakhali KM, Ansari A, Mohammad SA. Prescribing pattern of antibiotics in paediatric patients in the Jazan region, Kingdom of Saudi Arabia. RGUHS J Pharm Sci. 2014;4(3):120-4.

9. Woldu MA, Suleman S, Workneh N, Berhane H. Retrospective study of the pattern of antibiotic use in Hawassa University referral hospital pediatric ward, Southern Ethiopia. J Appl Pharm Sci. 2013;3(2):93.

10. Al-Ghazali MAA, Alakhali KM, Alawdi SM. Study of antibiotics prescribing pattern in paediatric patients of Thamar Province, in Republic of Yemen. J Appl Pharm. 2017;9:247.

11. Chaw PS, Schlinkmann KM, Raupach-Rosin H, Karch A, Pletz MW, Huebner J, et al. Antibiotic use on paediatric inpatients in a teaching hospital in the Gambia, a retrospective study. Antimicrob Resist Infect Control. 2018;7(1):82.

12. Labi AK, Obeng-Nkrumah N, Sunkwa-Mills G, Bediako-Bowan A, Akufo $\mathrm{C}$, Bjerrum $\mathrm{S}$, et al. Antibiotic prescribing in paediatric inpatients in Ghana: a multi-centre point prevalence survey. BMC Pediatr. 2018;18(1):391.

13. Zhang X, Zheng Y, Yang Y. Antibiotic prescription patterns in children and neonates in China. Lancet Glob Health. 2019;11.

14. Choudhury DK, Bezbaruah BK. Antibiotic prescriptions pattern in paediatric in-patient department Gauhati Medical College and Hospital, Guwahati. J Appl Pharm Sci 2013;3(08):144-8.

15. National list of essential medicine. 2015. Available at: https://apps.who.int/medicinedocs/documents/ s23087en/s23087en.pdf

16. Pradhan Mantri Bhartiya Jan Aushadhi Pariyojnaprice list. 2015:1-36.

17. Antibiotic policy, Government of India, Ministry of Health and Family welfare. 2015. Available at: https://pib.gov.in/newsite/PrintRelease.aspx?relid=11 7474

18. Directorate of General Health Services MHFW, New Delhi. National policy for containment of antimicrobial Resistance, India; 2011:1-55.

19. ReAct: Rational use of antibiotics- Elements of a plan. Available at: https://www.reactgroup.org/ toolbox/policy/elements-of-a-national-actionplan/rational-use-of-antibiotics. 2019:1-12.

20. Dr. Monica Bhatia, CIMS July to october ;2019.

Cite this article as: Devi LJ, Valte V, Joychandra O. A study of antibiotic used in paediatric inpatients at Jawaharlal Nehru Institute of Medical Sciences, Manipur: a retrospective study. Int J Basic Clin Pharmacol 2020;9:595-9. 